\title{
Development and validation of a CCD-laser aerosol detective system for measuring the ambient aerosol phase function
}

\author{
Yuxuan Bian ${ }^{1,2}$, Chunsheng Zhao ${ }^{2}$, Wanyun $\mathrm{Xu}^{3}$, Gang $\mathrm{Zhao}^{2}$, Jiangchuan $\mathrm{Tao}^{2}$, and Ye Kuang ${ }^{2}$ \\ ${ }^{1}$ State Key Laboratory of Severe Weather, Chinese Academy of Meteorological Sciences, Beijing, 100081, China \\ ${ }^{2}$ Department of Atmospheric and Oceanic Sciences, School of Physics, Peking University, Beijing, 100871, China \\ ${ }^{3}$ State Key Laboratory of Severe Weather \& Key Laboratory of Atmospheric Chemistry of CMA, Chinese Academy \\ of Meteorological Sciences, Beijing, 100081, China
}

Correspondence to: Chunsheng Zhao (zcs@pku.edu.cn)

Received: 28 November 2016 - Discussion started: 6 February 2017

Revised: 2 May 2017 - Accepted: 29 May 2017 - Published: 27 June 2017

\begin{abstract}
Aerosol phase function represents the angular scattering property of aerosols, which is crucial for understanding the climate effects of aerosols that have been identified as one of the largest uncertainties in the evaluation of radiative forcing. So far, there is a lack of instruments with which to measure the aerosol phase function directly and accurately in laboratory studies and in situ measurements. A portable instrument with high angular range and resolution has been developed for the measurement of the phase function of ambient aerosols in this study. The charge-coupled device-laser aerosol detective system (CCDLADS) measures the aerosol phase function both across a relatively wide angular range of $10-170^{\circ}$ and at a high resolution of $0.1^{\circ}$. The system includes a continuous laser, two charge-coupled device cameras and the corresponding fisheye lenses. The CCD-LADS was validated by both a laboratory study and a field measurement. The comparison between the aerosol phase function retrieved from CCD-LADS and Mie-scattering model shows good agreement. Compared with the TSI polar nephelometer, CCD-LADS has the advantages of wider detection range and better stability.
\end{abstract}

\section{Introduction}

The climate effect of aerosol optical properties is one of the greatest uncertainties in our understanding of climate change (Pachauri et al., 2014). Instruments such as the integrating nephelometer have often been used to measure the aerosol scattering coefficient in laboratory studies and field cam- paigns (Anderson et al., 1996; Heintzenberg and Charlson, 1996; Ma et al., 2011; Müller et al., 2011; Tao et al., 2014). However, besides the total scattering coefficient, the distribution of aerosol scattering at different directions also has a significant impact on the direct climate effect of aerosols (Kuang et al., 2015, 2016b). The aerosol phase function $(p(\theta))$ is defined to describe the angular distribution of the aerosol scattering intensity (van de Hulst, 1957). $p(\theta)$ is one of the important properties determining the contribution of aerosols to the radiative balance of the atmosphere (Andrews et al., 2006). Some parameters such as the asymmetry parameter and the hemispheric backscatter fraction estimated from $p(\theta)$ are of great importance to the retrieval of remote sensing measurements and in the simulation of atmospheric radiative transfer models (Muñoz et al., 2002). If the particle is assumed to be spherical, there is a comprehensive theory named the "Mie scattering theory" which describes the characteristics of aerosol scattering when the particle size is at the same scale as the wavelength of scattering light (Bohren and Huffman, 2008). $p(\theta)$ can also be calculated with the size and complex refractive index of particles by Mie scattering theory (Kim et al., 2010).

In past years, different research groups have developed several versions of polar nephelometers to measure how the scattering intensities of aerosol particles, cloud droplets and ice crystals change with scattering angle. Muñoz et al. (2001, 2010, 2011) mounted a photomultiplier tube (PMT) on a mechanical arm which can rotate around a point on the laser light path in the same plane with the laser beam to change the scattering angle of the signal captured by the PMT. Castag- 
ner and Bigio $(2006,2007)$ focused the light scattered at a single spot with different scattering angles to another single spot by using two parabolic reflectors next to the light path. A plane mirror was placed at that point to reflect the scattering signals with different angles to a PMT by rotation. These two styles of instruments measured the angular distribution of scattering signals by using the rotational mechanism. This design will lead to an obvious uncertainty because the signals were not measured simultaneously. Barkey et al. (2002, 2007) made the sample flow perpendicular and intersected it with the light path. Then many PMTs were mounted around the point of intersection in the same plane with the laser beam to capture the scattering signal from different scattering angles. The signals with different scattering angles were measured at the same time with this design. However, the angular resolution which is limited to larger than $8^{\circ}$ per point is relatively low because the PMTs cannot be mounted too close to each other. Curtis et al. $(2007,2008)$ used an elliptical mirror to reflect the scattering light to a charge-coupled device (CCD) detector for the detection of aerosol phase function. By using CCD as detector, this method can offer a better angle and time resolution at a wider range of scattering angles than the other methods above. It just needs one detector and there is no need to move the detector during the measurement. However, the structure of this design is too complicated to be used in field measurements.

Recently, McCrowey et al. (2013) developed a miniaturised polar nephelometer, which can be used in the in situ measurement based on the techniques of Curtis et al. (2007) and can then be calibrated in the laboratory using polystyrene latex (PSL) standard particles. A comparison between the results measured from this instrument and calculated from a Mie model showed a good agreement. The detection range of this instrument is from 20 to $155^{\circ}$ scattering angle. Besides these studies, the Aurora 4000 polar nephelometer (Ecotech Pty Ltd., Australia) is currently the only commercial instrument that can measure the aerosol phase function. This product has a structure similar to that of the integrating nephelometer, while a backscatter shutter that is able to be positioned at any angle between 10 and $90^{\circ}$ is mounted in the cavity to help the nephelometer measuring the light scattering from that angle through to $170^{\circ}$. The Aurora 4000 can only measure the aerosol phase function in a scattering angle range of $0-90^{\circ}$ for dry aerosols. These two instruments can be used to measure the scattering phase function of dry aerosols in in situ measurements.

In this paper, a novel instrument named "charge-coupled device-laser aerosol detective system" (CCD-LADS) based on the CCD imaging principle and the optical structure of the fisheye lens is developed to measure the ambient aerosol phase function in the field measurement at a wider range of detection angles and a higher accuracy. The validation in both laboratory and field measurement shows the ability of the CCD-LADS to measure the aerosol phase function.

\section{Instrumentation and methodology}

\subsection{Design of the instrument}

The CCD-LADS includes several main components: a highpower continuous laser emitter, two CCD cameras, optical filters and fisheye lenses. The laser and CCD cameras are mounted on tripods and controlled by a laptop. Each component is portable and on a scale of a few cubic decimetres.

The emitting system of the CCD-LADS is mainly built with a solid continuous laser emitter. Nd: YAG is used as the solid laser material as the wavelength of the emitter is $532 \mathrm{~nm}$. The transverse mode is near TEM00. The M2 factor is less than 2.0 while the divergence of the beam is less than $2.0 \mathrm{mrad}$. The diameter at the aperture is $3.0 \mathrm{~mm}$. The power of the laser is $1 \mathrm{~W}$. To change the polarisation state of the laser from linear to circular, a quarter-wave plate was mounted in front of the laser emitter. During the exposure time (a few minutes) of the image, the circular-polarisation light can be assumed to be unpolarised.

The receiving system of CCD-LADS has three main parts, the CCD cameras, the optical filters and the fisheye lenses. The SBIG model STF-8300 CCD imaging camera, which has the KAF-8300 CCD sensor (ON Semiconductor, Phoenix, AZ, USA $)$ is used. The area array $(17.96 \times 13.52 \mathrm{~mm})$ of pixels has 8.3 million $(3326 \times 2504)$ effective pixels, while each pixel is a square $5.4 \mu \mathrm{m}$ on a side. The exposure time is from $0.1 \mathrm{~s}$ to $1 \mathrm{~h}$. The A/D converter is 16 bit. Due to its outstanding performance, this product is often used in astronomical measurements and also measurements in the other research areas (Coenen et al., 2015). The quantum efficiency of the CCD is about $55 \%$ at $532 \mathrm{~nm}$, while the linearity error is about $10 \%$. This camera has an air-cooling unit to control the temperature of CCD.

The fisheye lens (Sigma Corp., Japan) has a $10 \mathrm{~mm}$ focus length and a F2.8 aperture. When this lens is used with a Nikon camera, the field of view can be $180^{\circ}$. Because of the size of the CCD arrays, when this lens is used with the STF- 8300 camera, the field of view is about $120^{\circ}$. The equisolid projection, which means that the solid angle of the object is directly proportional to the area on the CCD arrays, is used by this lens (Miyamoto, 1964). The modulation transfer function of the lens shows that, according to the size of the CCD sensor, the difference of the sensitivities from the centre to the corner is less than 5\% (http: //www.sigma-photo.co.jp/english/lens/wide/10_28/\#/data).

To filter out the background noise from the sky radiation, an optical filter (Thorlabs, Newton, NJ, USA) is mounted between the CCD camera and the lens. The filter has a $532 \pm 2 \mathrm{~nm}$ wavelength, and a $10 \pm 2 \mathrm{~nm}$ full width at half maximum, while the minimum transmission at the peak is $70 \%$.

Figure 1a is the sketch map of the geometric relationship of CCD-LADS. The laser is emitted horizontally, while a beam trap is used to receive the laser beam on the other 


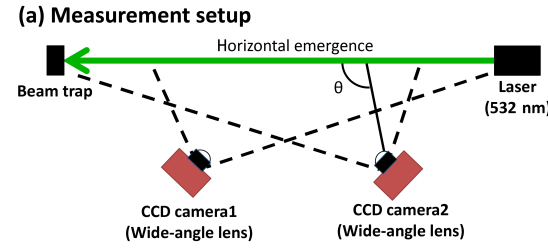

(c) Measured image

(b) Calibration setup

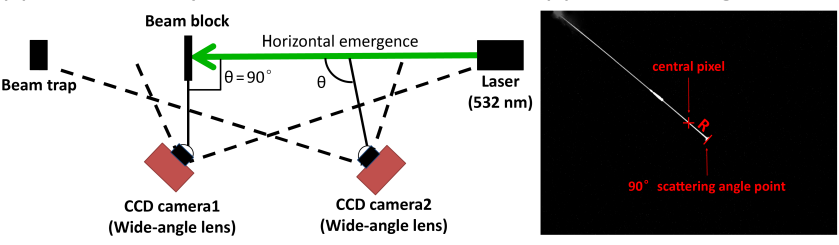

Figure 1. Sketch map of the geometric relationship and the sampling image of CCD-LADS.

side. Besides the laser beam, two CCD cameras with fisheye lenses are installed at the same altitude with the laser to capture the scattering signal from the laser beam, while the directions of the cameras are forward and backward. With the mounted lens, there is a one-to-one correspondence between the image of the laser beam captured by CCDs and the laser beam object according to the principle of image formation by lenses. When two CCD cameras are used in this system, the detective angle can be expanded to $10-170^{\circ}$. The angle resolution can reach $0.1^{\circ}$ per pixel. The scattering signal from 0 to 10 and 170 to $180^{\circ}$ cannot be detected, because the signal to noise ratio is significantly lower than the value needed to estimate the quantities effectively.

To decrease the total area of the instrument, the distance between the CCD cameras and the laser beam should be less than $1 \mathrm{~m}$. Therefore the CCD-LADS system covers an area $12 \mathrm{~m}$ long and $1 \mathrm{~m}$ wide. When the instrument is set up, the first step is to measure the relative position of the CCD cameras, the laser beam and the laser emitter. From the geometric relationship shown in Fig. 1, we can know that the light scattered at different position on the laser beam will be collected by different pixels on the $\mathrm{CCD}$, so that the scattering light at different angles can be retrieved from the image captured by CCD. Due to the open path structure of the CCD-LADS, the background noise is much higher in the daytime than at night-time. Currently, the CCD-LADS system can only estimate the nocturnal aerosol scattering phase function.

\subsection{Methodology}

\subsubsection{Data acquisition and preprocessing}

The data acquisition of CCD-LADS involves obtaining the angle-resolved scattering signals from images captured by two independent CCD systems and then merging the signals. Firstly, the CCD-LADS is set up as shown in Fig. 1a. The geometric relationships between the CCDs, laser emitter and light trap are measured by tape. Then the scattering angle of laser in the image should be calibrated. The direction of the CCD cameras are adjusted to make sure that the image from the laser goes through the centre of the pixel arrays of CCD. By using a beam block, the backscattering light is blocked from going into the CCD and the pixel related to the $90^{\circ}$ scattering angle can be referred from the calibrated image (Fig. 1d). Because of the equisolid projection is used by the lens, the distance from a point on the image on the CCD to the centre of the pixels can be calculated as $R=2 f \times \sin (\theta / 2)$, where $\theta$ is the angle in rad between a point in the real world and the optical axis, which goes from the centre of the image through the centre of the lens, $f$ is the focal length of the lens (Miyamoto, 1964). Therefore, the scattering angle, which is related to the centre of the image, can be calculated by introducing the distance between the centre of the pixels and the pixel related to the $90^{\circ}$ scattering angle in the calibrated image into the equation of the equisolid projection. In this way, each pixel on the image of laser will be associated with a scattering angle.

At the beginning of the measurement, the CCDs are cooled down to $-15^{\circ} \mathrm{C}$ to minimise the noise from dark current. Then a test image with a $10 \mathrm{~s}$ exposure time is captured to fix the exposure time of the measurement by evaluating the signal intensity of this image. Generally, the maximum of the signal intensity is tuned to about $2^{14}$ because the limitation is $2^{16}$. If the maximum increased to the limitation in an image, the exposure time will also be changed in the next image automatically. The exposure time of these two CCDs that were always about 5-60 s in the past observations and should be in complete accordance for the comparison. After the test image, a dark frame image is captured for each CCD by using a shutter in front of the lens. The dark current noise from the process and transmission of the signal can be subtracted during the procedure of image configuration by subtracting the dark frame image from the regular image (Fig. 2a). The images are captured automatically after these steps.

After the image has been captured, the scattering light of the laser beam is separated from the background noise in the image as in the following steps. Firstly, the central axis of the scattering signals of laser beam is fitted in the programme (the red line shown in Fig. 2b). Then the intensities of image on the perpendicular of this central axis (the blue line shown in Fig. 2b) are fitted with a normal distribution:

$f(x)=I_{0}+I \times \frac{1}{\sqrt{2 \pi} \sigma} \exp \left(-\frac{(x-\mu)^{2}}{2 \sigma^{2}}\right)$,

where $I_{0}$ is the intensity of the background noise, $I$ is the intensity of the scattering signal of the laser beam related to one scattering angle, $x$ represents the distance between the pixels on the perpendicular and central axis of the scattering signals. $\sigma$ and $\mu$ are the fitting parameters of the normal distribution. By combining this with the calibrated one-to-one correspondence between the image of the laser and the scat- 
(a) Dark current noise subtraction

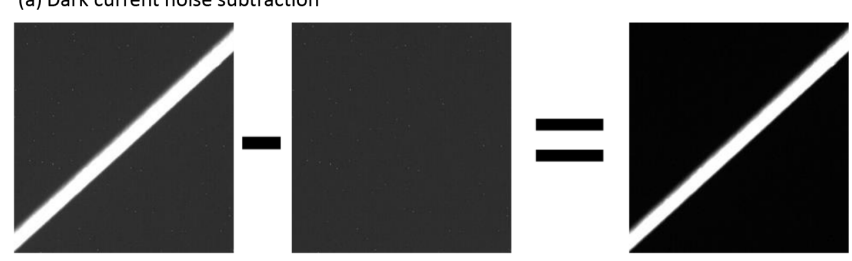

(b) Background noise subtraction

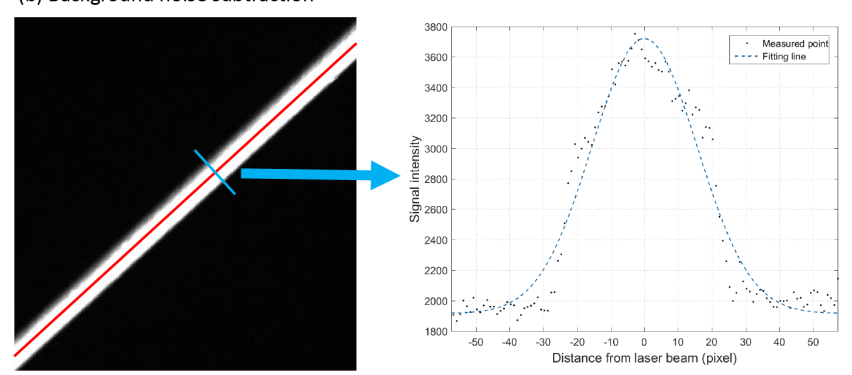

Figure 2. Noise subtraction of CCD-LADS: (a) dark current noise subtraction, (b) background noise subtraction.

tering angle, the angle-resolved scattering signals is obtained with the above steps of data acquisition.

When the angle-resolved signals from two CCDs are obtained, the change of signals with angles can be merged by following the steps below. Firstly, the minimum angle $\theta_{1}$ and maximum angle $\theta_{2}$ of the overlap angular region of signals from two CCDs are set as the boundary angle of data merging (shadow zone in Fig. 3). $\theta_{1}$ and $\theta_{2}$ are always around 50 and $80^{\circ}$, respectively. In this region, a transform coefficient with scattering angles $T(\theta)$ is calculated:

$T(\theta)=\frac{I_{1}(\theta)}{I_{2}(\theta)}$.

$I_{1}(\theta)$ is the signal with the scattering angle $\theta$ captured by the first CCD while $I_{2}(\theta)$ is that of the second CCD. The lifted signal $I_{2}^{\prime}(\theta)$ can be calculated by multiplying $I_{2}(\theta)$ with the average of $T(\theta)$ (Fig. 3). For the regions where $\theta<\theta_{1}$ or $\theta>\theta_{2}$, the signal $I_{1}(\theta)$ or $I_{2}^{\prime}(\theta)$ are used as the merged scattering signal $I(\theta)$, respectively. For the overlap region, a linear weighting average is calculated between $I_{1}(\theta)$ and $I_{2}^{\prime}(\theta)$,

$I(\theta)= \begin{cases}I_{1}(\theta), & \theta<\theta_{1} \\ \frac{\theta_{2}-\theta}{\theta_{2}-\theta_{1}} \times I_{1}(\theta)+\frac{\theta-\theta_{1}}{\theta_{2}-\theta_{1}} \times I_{2}^{\prime}(\theta), & \theta_{1} \leq \theta \leq \theta_{2} \\ I_{2}^{\prime}(\theta), & \theta>\theta_{2} .\end{cases}$

Using the method above, the merged signals with scattering angles $I(\theta)$ can be estimated.

\subsubsection{The retrieval algorithm to determine aerosol phase function}

Figure 4 shows the flow chart of the retrieval algorithm used to determine $p(\theta)$ from CCD-LADS measurements. According to the geometric structure of the CCD-LADS, the echo

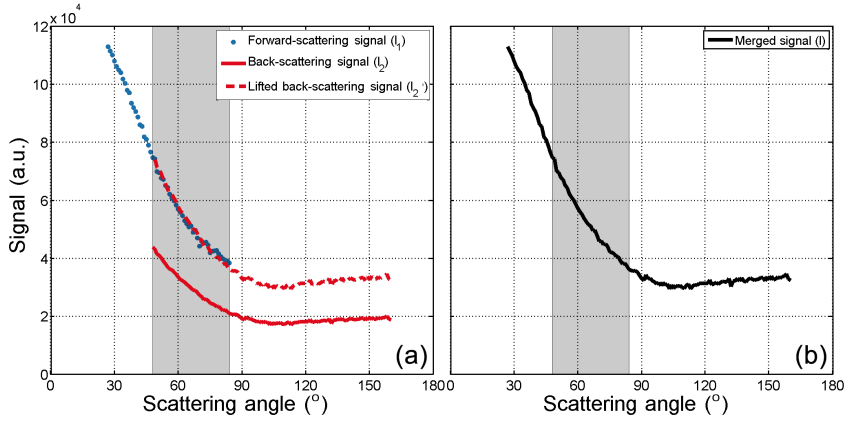

Figure 3. Signal merging of two CCD cameras. Besides the signals captured by the first CCD (blue dotted line) and the second CCD (red solid line), the lifted signal from the second CCD (red dashed line) is also shown in the left drawing. The merged signal is shown in the right drawing.

equation of CCD-LADS can be figured first:

$I(\theta)=N_{0} \tau_{Z} \tau_{R} \beta(\theta)$,

where $\beta(\theta)$ is the scattering function of atmospheric air molecules and aerosols, $\tau_{Z}$ and $\tau_{R}$ are the transmittances on the optical paths of laser emitting and scattering respectively, $N_{0}$ is the calibration factor that depends on the optical efficiency of the instrument. Depending on the area that the CCD-LADS covers, the longest distance between CCD cameras and the laser beam is less than $8 \mathrm{~m}$. In this range, an assumption that $\tau_{Z}=\tau_{R}=1$ can be established with a threshold that the visibility should be larger than $1.5 \mathrm{~km}$. The correlation between the visibility and extinction coefficient $\mathrm{k}_{\mathrm{ex}}$ can be expressed as $k_{\mathrm{ex}}=3 /$ visibility $(\mathrm{km})$ (Chen et al., 2012) which means that the assumption can be established if $\mathrm{k}_{\mathrm{ex}}$ is smaller than $2 \mathrm{~km}^{-1}$. In some extreme pollution processes with high concentrations of both aerosol and gaseous pollutants (Ma et al., 2011; Xu et al., 2011), the scattering and absorption of aerosols and gases $\left(\mathrm{NO}_{2}\right.$, Dixon, 1940 , $\mathrm{O}_{3}$, Burrows et al., 1999, etc.) may lead to extreme $k_{\mathrm{ex}}$ values. If the $k_{\mathrm{ex}}$ is more than $2 \mathrm{~km}^{-1}$, the assumption cannot be applied while the transmittance can be calculated with the measurement of visibility. With the assumption, Eq. (4) can be transformed to $I(\theta)=N_{0} \beta(\theta)$.

Scattering phase function $p(\theta)$ is the normalised angular distribution of the scattering function:

$p(\theta)=\frac{4 \pi \beta(\theta)}{\int_{4 \pi} \beta(\theta) \mathrm{d} \Omega}=\frac{2 \beta(\theta)}{\int_{0}^{180} \beta(\theta) \sin \theta \mathrm{d} \theta}=\frac{2 I(\theta)}{\int_{0}^{180} I(\theta) \sin \theta \mathrm{d} \theta}$.

Consequently, the scattering phase function can be calculated directly from $I(\theta)$ measured by CCD-LADS. If the scattering function of aerosols $\beta_{\text {aero }}(\theta)$ is known, the $p(\theta)$ can be calculated. Therefore, a retrieval algorithm is built to separate the scattering signals with angles into the scattering of aerosols and air molecules (shown in the dashed box in Fig. 4). 


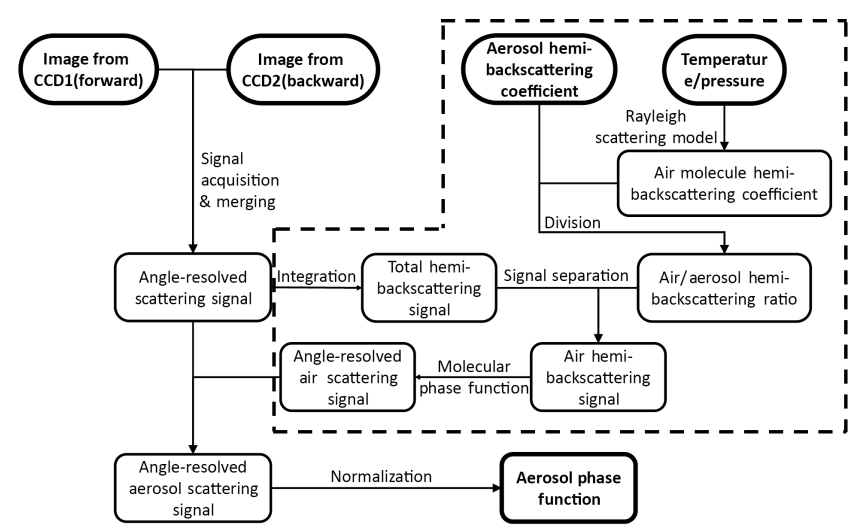

Figure 4. Flow chart of the retrieval algorithm used to determine aerosol phase function from CCD-LADS measurements (the processes in the dashed box are used to subtract the scattering signal of air molecules from the total scattering signal).

As the first step, the scattering coefficient of air molecules at near-surface level $k_{\mathrm{sc}-\text { air }}$ is calculated with the density of atmosphere by a Rayleigh scattering model:

$k_{\mathrm{sc}-\mathrm{air}}=\frac{8 \pi^{3}\left(m^{2}-1\right)^{2}}{3 n_{\mathrm{air}} \lambda^{4}}$,

where $n_{\text {air }}$ is the number density of air molecules, which depends on the surface pressure and temperature measured by the weather station. $m$ is the index of refraction of atmosphere, which depends on $n_{\text {air }}$ and the wavelength of the laser $\lambda$. The hemispheric backscattering coefficient of air molecules $k_{\mathrm{bsc}-\text { air }}$ is a half of $k_{\mathrm{sc}-\text { air }}$ (Bohren and Huffman, 2008).

To resolve the ratio between the air molecules and the total hemispheric scattering $R_{\text {air }}=\frac{k_{\text {bcc-air }}}{k_{\text {bsc-air }}+k_{\text {bsc-aero }}}$, the hemispheric backscattering coefficient of aerosols $k_{\text {bsc-aero }}$ is measured with an integrating nephelometer here.

To solve the intensity of the total hemispheric backscattering scattering signals $I_{\mathrm{bsc}}$, the angle-resolved scattering signals should be integrated from a 90 to $180^{\circ}$ scattering angle. Because of the detective angular range of CCD-LADS is $10-170^{\circ}$, the angular truncation correction is necessary to resolve the hemispheric scattering intensity. For the backward angular truncation, the scattering intensity in that range is assumed to be equal to the scattering intensity at the largest scattering angle that CCD-LADS can measured. After the correction above, the corrected intensity $I^{\prime}(\theta)$ is used to obtain $I_{\mathrm{bsc}}$ :

$I_{\mathrm{bsc}}=\int_{0}^{2 \pi} \int_{\pi / 2}^{\pi} I^{\prime}(\theta) \sin \theta \mathrm{d} \theta \mathrm{d} \varphi$.

Then the angle-resolved scattering signals of air molecules can be calculated with a molecular phase function (Bohren and Huffman, 2008):

$I_{\text {air }}(\theta)=\frac{3\left(1+\cos ^{2} \theta\right)}{4} \times \frac{I_{\mathrm{bsc}} \times R_{\mathrm{air}}}{2 \pi}$,

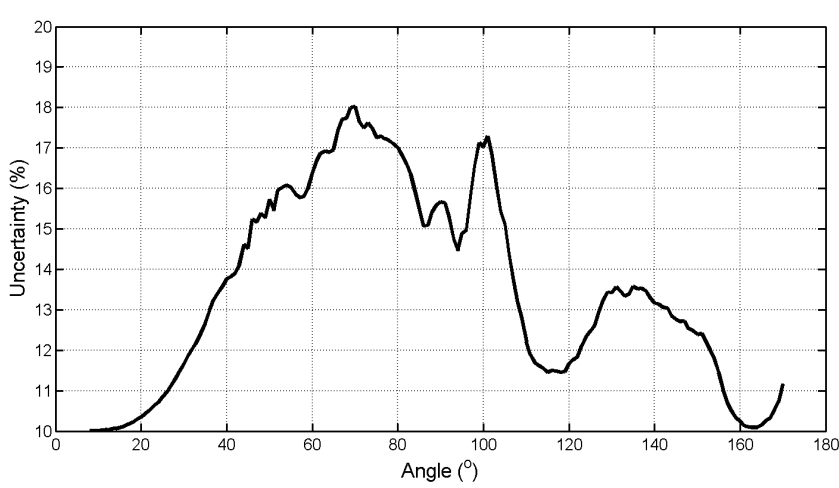

Figure 5. Uncertainties of the merged angle-resolved signal from CCD-LADS measurement.

where $I_{\text {air }}(\theta)$ is the calculated angle-resolved scattering signals of air molecules. According to Eq. (5), the aerosol phase function $p_{\text {aero }}(\theta)$ can be estimated as

$p_{\text {aero }}(\theta)=\frac{2\left(I(\theta)-I_{\text {air }}(\theta)\right)}{\int_{0}^{180}\left(I(\theta)-I_{\text {air }}(\theta)\right) \sin \theta \mathrm{d} \theta}$.

\subsubsection{Error analysis}

Two types of uncertainties determine the error of the retrieved aerosol phase function: the measurement errors caused by the processes of obtaining the angle-resolved signals and an error introduced by the retrieval algorithm.

There are two sources of measurement errors in the data acquisition processes introduced in Sect. 2.2.1. Firstly, the measurement error of CCD used in the CCD-LADS is $10 \%$ according to the related manual. The relative difference between the fitted normal distribution introduced in Eq. (1) and the measured signal in the laboratory study is $8.8 \% \pm 1.5 \%$, which can also certify the $10 \%$ measuring error on $I$ introduced by the manual of CCD. Secondly, the measurement of the geometric relationship will lead to a relative error of $5 \%$ at the most on the scattering angle $\theta$ introduced by the resolution and accuracy of the used tools.

The relative errors on the merged angle-resolved signals $I(\theta)$ can be derived by applying a standard propagation of errors to Eq. (3) (Bevington and Robinson, 2003):

$\left(\frac{\Delta I}{I}\right)^{2}=F_{I_{1}}\left(\frac{\Delta I_{1}}{I_{1}}\right)^{2}+F_{I_{2}^{\prime}}\left(\frac{\Delta I_{2}^{\prime}}{I_{2}^{\prime}}\right)^{2}+F_{\theta}\left(\frac{\Delta \theta}{\theta}\right)^{2}$,

where $\Delta$ means the standard deviation of variables, $\frac{\Delta x}{x}$ is equal to the relative error of $x$ and the propagation factor $F_{x}$ is defined as $F_{x}=\left(\frac{x}{I} \frac{\partial I}{\partial x}\right)^{2}$. By substituting the relative errors and the average signals in Eq. (10), the uncertainties on $I(\theta)$ are calculated as a distribution with an angle-resolved distribution shown in Fig. 5. The values of uncertainties on $I(\theta)$ are between 10 and $19 \%$, and they vary with angle.

The uncertainties of the retrieval algorithm are introduced by the uncertainties of the input parameters. There are three 
groups of input parameters in the retrieval algorithm: merged angle-resolved signals, aerosol hemi-backscattering coefficient and temperature/pressure. The errors of the temperature and pressure are about $0.1 \mathrm{~K}$ and $0.1 \mathrm{hPa}$ (Box and Steffen, 2001 ), which will lead to a $0.02 \%$ uncertainty on $k_{\text {bsc-air }}$. Combined the $10 \%$ uncertainties on the measured $k_{\text {bsc-aero }}$ (Heintzenberg et al., 2006), the uncertainty of $R_{\text {air }}$ can be calculated as $7 \%$ with the algorithm in Sect. 2.2.2. According to the algorithm shown in Fig. 4, the uncertainty of the retrieved aerosol phase function are mainly dominated by the uncertainties of the merged signal shown in Fig. 5, and also influenced by the uncertainty of $R_{\text {air }}$ in a way.

\section{Results}

\subsection{Laboratory results}

To validate the ability of the CCD-LADS to measure the aerosol phase function, an indoor experiment was held in the laboratory in the Physics Building at Peking University during 7-8 November 2015. The time resolution of CCDLADS was set to $60 \mathrm{~s}$ during the experiment, while the angular detection ranged from 10 to $170^{\circ}$. The aerosol scattering coefficient, number size distribution, mass concentration of black carbon particles, ambient temperature and relative humidity were measured with an integrating nephelometer (Model 3563, TSI, Inc., Shoreview, MN, USA), a scanned mobility particle sizer (SMPS; Model 3936, TSI, Inc., Shoreview, MN, USA), an aerodynamic particle sizer (APS; Model 3321, TSI, Inc., Shoreview, MN, USA), a micro-Aethalometer (Model AE51, Magee Scientific, Berkeley, CA, USA) and a dew-point chilled mirror sensor (Edgetech DewMaster), respectively.

Figure 6 shows the time series of several quantities during the laboratory experiment. The scattering/hemispheric backscattering coefficient of aerosols at $525 \mathrm{~nm}$ wavelength shown in Fig. $6 \mathrm{~b}$ and the mass concentration of black carbon particles shown in Fig. 6c reveal the same pattern that first declines and climbs up afterwards. The same pattern can be discovered in the time series of particle number size distributions shown in Fig. 6d. The variation reflects the slow exchange between the indoor and outdoor air. The peak diameter of aerosol number size distribution was still around $100 \mathrm{~nm}$, but it had a slight shift during the experiment. Therefore, the fine particles are dominant in the laboratory. The single scattering albedo (SSA) shown in Fig. 6c was around 0.85 which means that the black carbon aerosol took up a relatively large proportion of the aerosol species, resulting in strong particle light absorption ability.

Having combined the particle number size distributions measured with SMPS/APS and the mass concentration of black carbon aerosols measured with AE51 (Fig. 6) into a modified Mie-scattering model, the aerosol optical properties including the aerosol phase function could be modelled (Ma
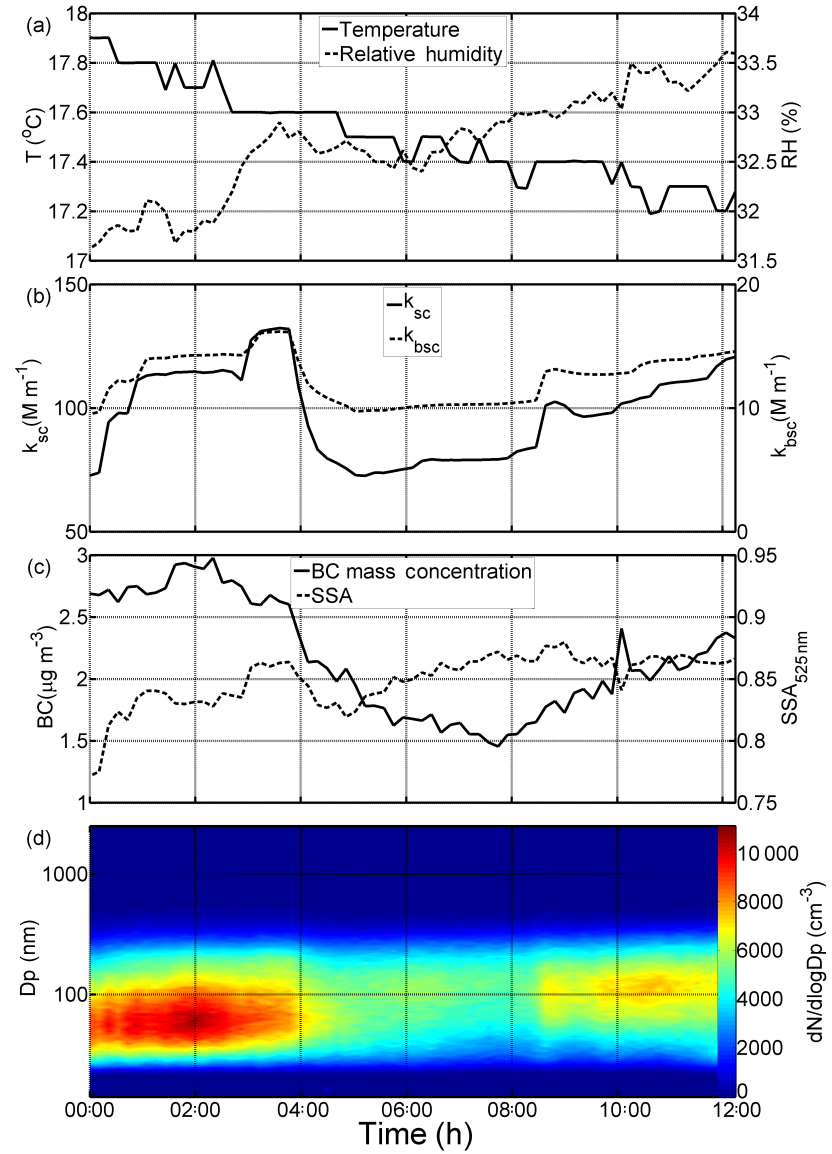

Figure 6. Time series of (a) temperature (solid line) and relative humidity (dashed line) in the laboratory, (b) scattering coefficient (solid line) and hemispheric backscattering coefficient (dashed line) of aerosols at $525 \mathrm{~nm}$ wavelength, (c) mass concentration of black carbon particles (solid line) and single scattering albedo of aerosols at $525 \mathrm{~nm}$ wavelength (dashed line), (d) PNSD of aerosols during the laboratory study at Peking University in 2015.

et al., 2011). In this study (both laboratory and field study), the refractive index used for black carbon component is 1.95$0.79 i$ (Seinfeld and Pandis, 2006), and for non-absorbing component it is $1.53-10^{-7} i$ (Wex et al., 2002). The mass ratio between two different mixing states (external or coreshell, which are two different ways black carbon and nonabsorbing aerosols are mixed) of black carbon aerosols is assumed to be $1: 1$ according to the result of Ma et al. (2012). Figure 7 shows the comparison between the aerosol phase functions retrieved with the CCD-LADS retrieval algorithm, modelled with the modified Mie model and offered by the aerosol classification from the Cloud-Aerosol Lidar and Infrared Pathfinder Satellite Observations (CALIPSO) aerosol products (Omar et al., 2009). The CALIPSO aerosol classifications are based on the cluster analysis of the AErosol RObotic NETwork (AERONET) measurements to determine characteristic aerosol types (Omar et al., 2005). Here the 
red solid line shows the retrieved $p(\theta)$ from the CCDLADS measurements with the retrieval algorithm introduced in Sect. 2.2.2, while the brown dashed line shows the retrieved $p(\theta)$ from CCD-LADS directly without considering the scattering influence of air molecules. The blue dashed line shows the modelled result, and the other dotted lines express the aerosol phase functions of different aerosol types from CALIPSO aerosol classification. The uncertainties of the retrieved $p(\theta)$ and simulated $p(\theta)$ with the Mie model, which is about $30 \%$ (Ma et al., 2011), are shown as error bars. The result shows that the comparison between the modelled $p(\theta)$ and the $p(\theta)$ retrieved with the retrieval algorithm shows a better agreement than the comparison between the modelled $p(\theta)$ and the $p(\theta)$ retrieved from the CCDLADS measurements directly, especially for the backward scattering. The reasons for this phenomenon is that the scattering coefficients of aerosols and air molecules are closer to each other for the backward scatter than for the forward scatter based on the background and that the total scattering coefficient of aerosols is always much higher than that of air molecules. The comparison also shows that the retrieved $p(\theta)$ is closer to the aerosol phase function of the biomass burning aerosol among the six aerosol types classified from CALIPSO aerosol products. Compared with the other aerosol types, the biomass burning aerosol represents a better absorption ability due to the larger percentage of black carbon aerosol and organic aerosol, and also a smaller effective diameter around $100 \mathrm{~nm}$ (Omar et al., 2005; Rissler et al., 2006; Zhu et al., 2017). The SSA and particle number size distribution of aerosols during the experiment shown in Fig. 6 also have similar characteristics to the biomass burning aerosol.

To further validate the quality of the retrieved result from the CCD-LADS measurement, a comparison was also carried out among the $p(\theta)$ at $42^{\circ}$ scattering angle resolved with different methods (Fig. 8). The $p(\theta)$ at $42^{\circ}$ scattering angle is relatively typical and comparable because $42^{\circ}$ is the scattering angle used in the forward scattering visibility sensor (Kessner et al., 2013). The result of the comparison shows that the $p(\theta)$ from CCD-LADS measurement and Mie model have the same pattern and the average difference in the absolute values between these two $p(\theta)$ is less than $10 \%$.

\subsection{Field measurements}

During January 2016, a comprehensive field campaign focused on air pollution in winter was conducted on the roof of a school building at Yanqi campus of the University of Chinese Academy of sciences (UCAS) in the Huairou district, Beijing $\left(40^{\circ} 24^{\prime} \mathrm{N}, 116^{\circ} 40^{\prime} \mathrm{E}, 91 \mathrm{~m}\right.$ a.s.l.). The observatory is $60 \mathrm{~km}$ away from the centre of Beijing and is at the edge of the North China Plain (NCP), which makes it suitable for measuring the regional pollution properties of the NCP (Ma et al., 2016). During the campaign, all the instruments except for the CCD-LADS were housed in a laboratory with a steady

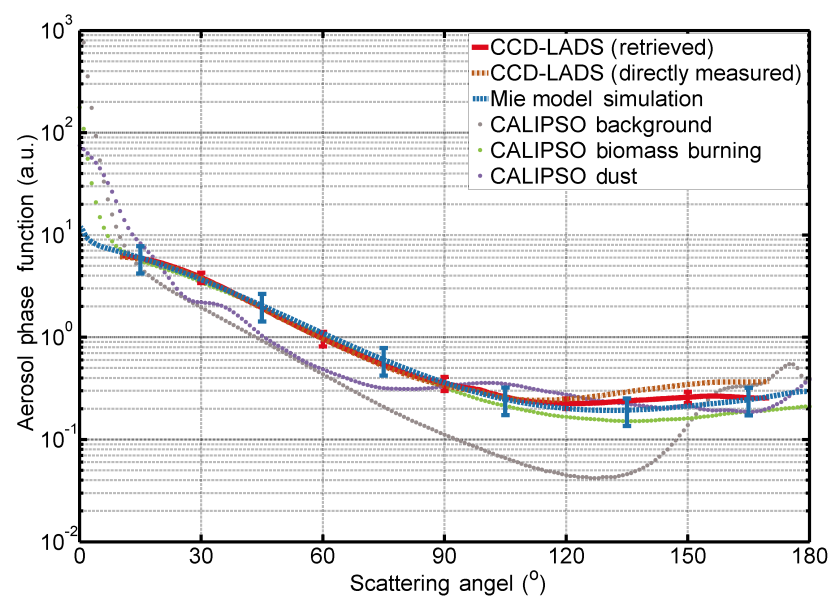

Figure 7. Comparison between aerosol phase function obtained from CCD-LADS measurements (red solid line shows the result estimated with the retrieval algorithm, brown dashed line shows that estimated directly with the measurements), modelled with modified Mie model (blue dashed line) and offered by previous studies with CALIPSO (different colours of dotted lines represent different aerosol types).

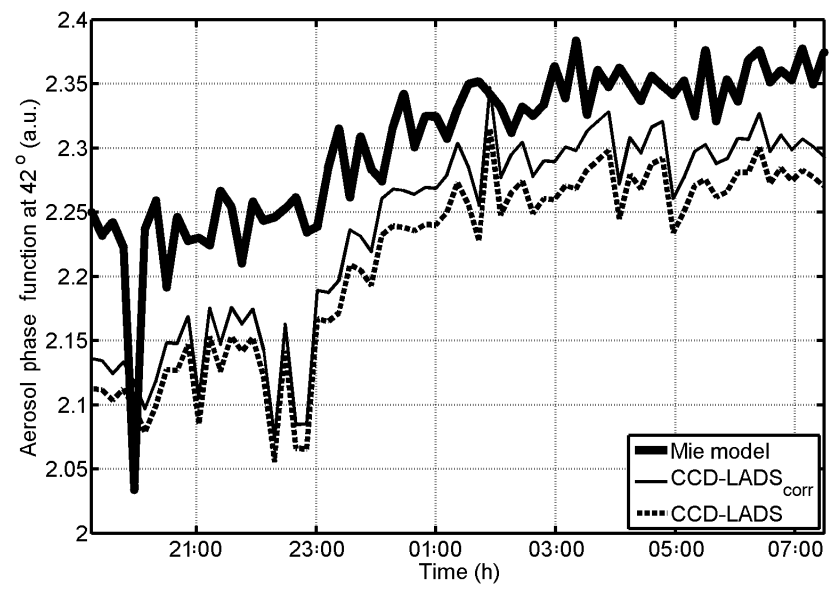

Figure 8. Comparison between aerosol phase function at $42^{\circ}$ scattering angle obtained from CCD-LADS measurements (results estimated with the retrieval algorithm are shown with a fine solid line, while the values estimated directly with the measurements are shown with a dashed line) and modelled with a modified Mie model (shown with a bold solid line).

room temperature of $20^{\circ} \mathrm{C}$. The aerosols were sampled from an inlet $5 \mathrm{~m}$ higher than the ground and then dried to a relative humidity less than $30 \%$ before flowing into the laboratory to measure the aerosol number size distribution, scattering coefficient, phase function and the mass concentration of black carbon aerosols at a dry condition. The CCD-LADS was mounted outside the laboratory at the same altitude to measure the scattering phase function of ambient aerosols. Depending on the limitation of the ambient condition, the 


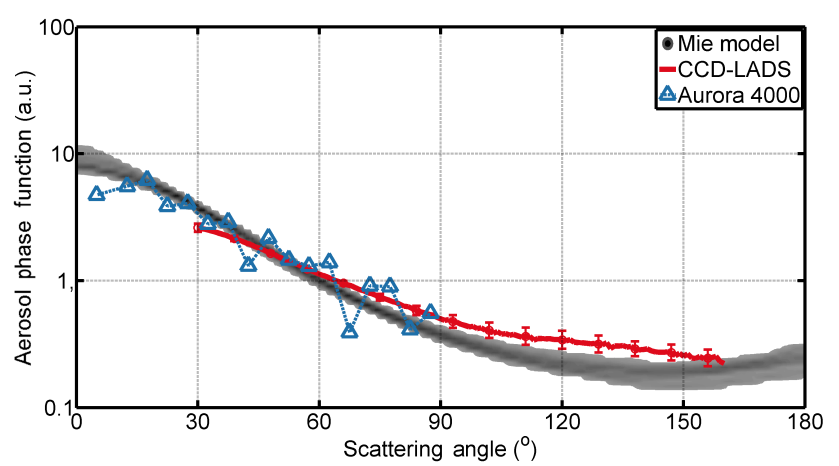

Figure 9. Comparison between aerosol phase function retrieved from CCD-LADS measurements (red line shows the average value, the error bar shows the standard deviation), measured from Aurora 4000 polar nephelometer (blue triangle) and modelled with modified Mie model (grayscale map).

angular detection range of the CCD-LADS was $30-160^{\circ}$ in this campaign.

During the field measurement, the scattering phase function of dry aerosols could be resolved in two ways, with Aurora 4000 polar nephelometer measurements or with the modified Mie-scattering model with the related aerosol measurements. Under high relative humidity condition, aerosol particles will absorb moisture in the atmosphere and exhibit hygroscopic growth significantly (Bian et al., 2014; Chen et al., 2014; Kuang et al., 2016a), and hence the scattering properties of ambient and dry aerosols are totally different. Therefore, the data collected at a relative humidity above $70 \%$ were eliminated from the comparison between the scattering phase functions of dry and ambient aerosols obtained by different methods. Figure 9 shows the result of the comparison mentioned above. The results from the three methods are consistent with one another in the overlap of the detectable scattering angular range. Compared with the other results, the retrieval of CCD-LADS measurement enhances the backward scattering fraction of aerosol. This might be caused by the angular range $\left(30-160^{\circ}\right)$, which did not reach $10-170^{\circ}$ and therefore might have increased errors in retrieving the angular distribution of aerosol scattering. The $p(\theta)$ from Aurora 4000 measurements have the similar average pattern with the results from other methods, but the deviation of its pattern is obvious. Compared to the Aurora 4000 results, there are two significant advantages of CCD-LADS: wider detection range and better stability.

\section{Discussions and conclusions}

A novel instrument named charge-coupled device-laser aerosol detective system (CCD-LADS) was developed to measure the nocturnal ambient aerosol phase function in the ambient atmosphere at a wider range of detection angles and a higher accuracy. The validation in both laboratory and field measurement shows the ability of CCD-LADS to measure the aerosol phase function. A laser is emitted horizontally, while two CCD cameras with fisheye lenses are installed besides the laser beam at the same altitude to capture the scattering signal from the laser beam with the cameras facing forward and backward. Then the signal captured by the two cameras are merged into one signal curve. The detectable angular range is from 10 to $170^{\circ}$, while the angle resolution reach $0.1^{\circ}$ per pixel. A retrieval algorithm is developed to subtract the influence of air molecule scattering with the integrating nephelometer and weather station measurements. The uncertainties of CCD-LADS were discussed.

To validate the ability of CCD-LADS to measure the aerosol phase function, an indoor experiment was held in the laboratory of the Physics Building at Peking University during 7-8 November 2015 . During the experiment, the angular detection range was from 10 to $170^{\circ}$. The comparison between the modelled $p(\theta)$ and the retrieved $p(\theta)$ shows excellent agreement. Both of them are close to the aerosol phase function of the biomass burning aerosol from CALIPSO aerosol products. The comparison result is reasonable, because the SSA and particle number size distribution of aerosols during the experiment also had similar characteristics to the biomass burning aerosol. The comparison of the $p(\theta)$ at $42^{\circ}$ scattering angle acquired by different methods also shows good agreements for both patterns and absolute values.

During January 2016, a comprehensive field campaign focused on air pollution in winter was organised at the roof of a school building in Yanqi campus of UCAS. Depending on the limitation of the ambient condition, the angular detection range of the CCD-LADS was $30-160^{\circ}$ in this campaign. The retrieved aerosol phase function with CCD-LADS measurements is consistent with both the Aurora 4000 measurement and the modified Mie model results in the overlap region of the detectable scattering angular range. Compared with the Aurora 4000 measurements during this campaign, the CCDLADS measurements are steadier.

Both the laboratory experiment and the field measurement have demonstrated that the CCD-LADS is a robust instrument, fully capable of measuring the ambient aerosol phase function under different conditions. Overall, compared with the laboratory-scale instruments, the CCD-LADS measured aerosol phase functions with a wider angular range and at a higher angular resolution.

Data availability. The averaged retrieved aerosol phase function used to create Fig. 7 is attached in Supplement. The CALIPSO aerosol classification data are listed in the reference. The entire data set can be accessed by request to the corresponding author at zcs@pku.edu.cn.

The Supplement related to this article is available online at https://doi.org/10.5194/amt-10-2313-2017-supplement. 
Competing interests. The authors declare that they have no conflict of interest.

Acknowledgements. This work is supported by the National Natural Science Foundation of China (41590872, 41375134).

Edited by: Thomas Wagner

Reviewed by: two anonymous referees

\section{References}

Anderson, T. L., Covert, D. S., Marshall, S. F., Laucks, M. L., Charlson, R. J., Waggoner, A. P., Ogren, J. A., Caldow, R., Holm, R. L., Quant, F. R., Sem, G. J., Wiedensohler, A., Ahlquist, N. A., and Bates, T. S.: Performance Characteristics of a High-Sensitivity, ThreeWavelength, Total Scatter/Backscatter Nephelometer, J. Atmos. Ocean. Tech., 13, 967-986, https://doi.org/10.1175/15200426(1996)013<0967:PCOAHS>2.0.CO;2, 1996.

Andrews, E., Sheridan, P. J., Fiebig, M., McComiskey, A., Ogren, J. A., Arnott, P., Covert, D., Elleman, R., Gasparini, R., Collins, D., Jonsson, H., Schmid, B., and Wang, J.: Comparison of methods for deriving aerosol asymmetry parameter, J. Geophys. Res.Atmos., 111, D05S04, https://doi.org/10.1029/2004JD005734, 2006.

Barkey, B., Bailey, M., Liou, K.-N., and Hallett, J.: Light-scattering properties of plate and column ice crystals generated in a laboratory cold chamber, Appl. Optics, 41, 5792-5796, 2002.

Barkey, B., Paulson, S. E., and Chung, A.: Genetic Algorithm Inversion of Dual Polarization Polar Nephelometer Data to Determine Aerosol Refractive Index, Aerosol Sci. Tech., 41, 751-760, 2007.

Bevington, P. R. and Robinson, D. K.: Data reduction and error analysis, Third Edn., Physical Science - Astronomy, McGrawHill Education, 336 pp., 2003.

Bian, Y. X., Zhao, C. S., Ma, N., Chen, J., and Xu, W. Y.: A study of aerosol liquid water content based on hygroscopicity measurements at high relative humidity in the North China Plain, Atmos. Chem. Phys., 14, 6417-6426, https://doi.org/10.5194/acp14-6417-2014, 2014.

Bohren, C. F. and Huffman, D. R.: Absorption and scattering of light by small particles, John Wiley \& Sons, New York, 2008.

Box, J. E. and Steffen, K.: Sublimation on the Greenland Ice Sheet from automated weather station observations, J. Geophys. Res.-Atmos., 106, 33965-33981, https://doi.org/10.1029/2001jd900219, 2001

Burrows, J. P., Richter, A., Dehn, A., Deters, B., Himmelmann, S., Voigt, S., and Orphal, J.: ATMOSPHERIC REMOTE-SENSING REFERENCE DATA FROM GOME - 2. TEMPERATUREDEPENDENT ABSORPTION CROSS SECTIONS OF $\mathrm{O}_{3}$ IN THE 231-794NM RANGE, J. Quant. Spectrosc. Ra., 61, 509517, https://doi.org/10.1016/S0022-4073(98)00037-5, 1999.

Castagner, J.-L. and Bigio, I. J.: Polar nephelometer based on a rotational confocal imaging setup, Appl. Optics, 45, 2232-2239, 2006.

Castagner, J.-L. and Bigio, I. J.: Particle sizing with a fast polar nephelometer, Appl. Optics, 46, 527-532, 2007.
Chen, J., Zhao, C. S., Ma, N., Liu, P. F., Göbel, T., Hallbauer, E., Deng, Z. Z., Ran, L., Xu, W. Y., Liang, Z., Liu, H. J., Yan, P., Zhou, X. J., and Wiedensohler, A.: A parameterization of low visibilities for hazy days in the North China Plain, Atmos. Chem. Phys., 12, 4935-4950, https://doi.org/10.5194/acp12-4935-2012, 2012.

Chen, J., Zhao, C. S., Ma, N., and Yan, P.: Aerosol hygroscopicity parameter derived from the light scattering enhancement factor measurements in the North China Plain, Atmos. Chem. Phys., 14, 8105-8118, https://doi.org/10.5194/acp-14-8105-2014, 2014.

Coenen, J. W., Arnoux, G., Bazylev, B., Matthews, G. F., Jachmich, S., Balboa, I., Clever, M., Dejarnac, R., Coffey, I., Corre, Y., Devaux, S., Frassinetti, L., Gauthier, E., Horacek, J., Knaup, M., Komm, M., Krieger, K., Marsen, S., Meigs, A., Mertens, P., Pitts, R. A., Puetterich, T., Rack, M., Stamp, M., Sergienko, G., Tamain, P., and Thompson, V.: ELM induced tungsten melting and its impact on tokamak operation, J. Nucl. Mater., 463, 7884, https://doi.org/10.1016/j.jnucmat.2014.08.062, 2015.

Curtis, D. B., Aycibin, M., Young, M. A., Grassian, V. H., and Kleiber, P. D.: Simultaneous measurement of light-scattering properties and particle size distribution for aerosols: Application to ammonium sulfate and quartz aerosol particles, Atmos. Environ., 41, 4748-4758, 2007.

Curtis, D. B., Meland, B., Aycibin, M., Arnold, N. P., Grassian, V. H., Young, M. A., and Kleiber, P. D.: A laboratory investigation of light scattering from representative components of mineral dust aerosol at a wavelength of $550 \mathrm{~nm}$, J. Geophys. Res.-Atmos., 113, D08210, https://doi.org/10.1029/2007JD009387, 2008.

Dixon, J. K.: The Absorption Coefficient of Nitrogen Dioxide in the Visible Spectrum, J. Chem. Phys., 8, 157-160, https://doi.org/10.1063/1.1750622, 1940.

Heintzenberg, J. and Charlson, R. J.: Design and Applications of the Integrating Nephelometer: A Review, J. Atmos. Ocean. Tech., 13, 987-1000, https://doi.org/10.1175/15200426(1996)013<0987:DAAOTI>2.0.CO;2, 1996.

Heintzenberg, J., Wiedensohler, A., Tuch, T. M., Covert, D. S., Sheridan, P., Ogren, J. A., Gras, J., Nessler, R., Kleefeld, C., Kalivitis, N., Aaltonen, V., Wilhelm, R.-T., and Havlicek, M.: Intercomparisons and Aerosol Calibrations of 12 Commercial Integrating Nephelometers of Three Manufacturers, J. Atmos. Ocean. Tech., 23, 902-914, https://doi.org/10.1175/jtech1892.1, 2006.

van de Hulst, H. C.: Light scattering by small particles, Dover Publications, New York, 1957

Kessner, A. L., Wang, J., Levy, R. C., and Colarco, P. R.: Remote sensing of surface visibility from space: A look at the United States East Coast, Atmos. Environ., 81, 136-147, 2013.

Kim, H., Barkey, B., and Paulson, S. E.: Real refractive indices of $\alpha$ and $\beta$-pinene and toluene secondary organic aerosols generated from ozonolysis and photo-oxidation, J. Geophys. Res.-Atmos., 115, D24212, https://doi.org/10.1029/2010jd014549, 2010.

Kuang, Y., Zhao, C. S., Tao, J. C., and Ma, N.: Diurnal variations of aerosol optical properties in the North China Plain and their influences on the estimates of direct aerosol radiative effect, Atmos. Chem. Phys., 15, 5761-5772, https://doi.org/10.5194/acp15-5761-2015, 2015.

Kuang, Y., Zhao, C. S., Ma, N., Liu, H. J., Bian, Y. X., Tao, J. C., and $\mathrm{Hu}, \mathrm{M}$.: Deliquescent phenomena of ambient aerosols on the North China Plain, Geophys. Res. Lett., 43, 8744-8750, $2016 \mathrm{a}$. 
Kuang, Y., Zhao, C. S., Tao, J. C., Bian, Y. X., and Ma, N.: Impact of aerosol hygroscopic growth on the direct aerosol radiative effect in summer on North China Plain, Atmos. Environ., 147, 224 233, $2016 b$.

Ma, N., Zhao, C. S., Nowak, A., Müller, T., Pfeifer, S., Cheng, Y. F., Deng, Z. Z., Liu, P. F., Xu, W. Y., Ran, L., Yan, P., Göbel, T., Hallbauer, E., Mildenberger, K., Henning, S., Yu, J., Chen, L. L., Zhou, X. J., Stratmann, F., and Wiedensohler, A.: Aerosol optical properties in the North China Plain during HaChi campaign: an in-situ optical closure study, Atmos. Chem. Phys., 11, 5959-5973, https://doi.org/10.5194/acp-11-5959-2011, 2011.

Ma, N., Zhao, C. S., Müller, T., Cheng, Y. F., Liu, P. F., Deng, Z. Z., Xu, W. Y., Ran, L., Nekat, B., van Pinxteren, D., Gnauk, T., Müller, K., Herrmann, H., Yan, P., Zhou, X. J., and Wiedensohler, A.: A new method to determine the mixing state of light absorbing carbonaceous using the measured aerosol optical properties and number size distributions, Atmos. Chem. Phys., 12, 23812397, https://doi.org/10.5194/acp-12-2381-2012, 2012.

Ma, N., Zhao, C., Tao, J., Wu, Z., Kecorius, S., Wang, Z., Größ, J., Liu, H., Bian, Y., Kuang, Y., Teich, M., Spindler, G., Müller, K., van Pinxteren, D., Herrmann, H., Hu, M., and Wiedensohler, A.: Variation of CCN activity during new particle formation events in the North China Plain, Atmos. Chem. Phys., 16, 8593-8607, https://doi.org/10.5194/acp-16-8593-2016, 2016.

McCrowey, C. J., Tinilau, S. S., Calderon, G., Koo, J.-E., and Curtis, D. B.: A Portable High-Resolution Polar Nephelometer for Measurement of the Angular Scattering Properties of Atmospheric Aerosol: Design and Validation, Aerosol Sci. Tech., 47, 592-605, 2013.

Miyamoto, K.: Fish Eye Lens, J. Opt. Soc. Am., 54, 1060-1061, https://doi.org/10.1364/JOSA.54.001060, 1964.

Müller, T., Laborde, M., Kassell, G., and Wiedensohler, A.: Design and performance of a three-wavelength LED-based total scatter and backscatter integrating nephelometer, Atmos. Meas. Tech., 4, 1291-1303, https://doi.org/10.5194/amt-4-1291-2011, 2011.

Muñoz, O., Volten, H., de Haan, J. F., Vassen, W., and Hovenier, J. W.: Experimental determination of scattering matrices of randomly oriented fly ash and clay particles at 442 and $633 \mathrm{~nm}$, J. Geophys. Res.-Atmos., 106, 22833-22844, https://doi.org/10.1029/2000JD000164, 2001.

Muñoz, O., Volten, H., de Haan, J. F., Vassen, W., and Hovenier, J. W.: Experimental determination of the phase function and degree of linear polarization of El Chichón and Pinatubo volcanic ashes, J. Geophys. Res.-Atmos., 107, ACL 4-1-ACL 4-8, https://doi.org/10.1029/2001JD000983, 2002.

Muñoz, O., Moreno, F., Guirado, D., Ramos, J. L., López, A., Girela, F., Jerónimo, J. M., Costillo, L. P., and Bustamante, I.: Experimental determination of scattering matrices of dust particles at visible wavelengths: The IAA light scattering apparatus, J. Quant. Spectrosc. Ra., 111, 187-196, https://doi.org/10.1016/j.jqsrt.2009.06.011, 2010.

Muñoz, O. and Hovenier, J. W.: Laboratory measurements of single light scattering by ensembles of randomly oriented small irregular particles in air. A review, J. Quant. Spectrosc. Ra., 112, 1646-1657, https://doi.org/10.1016/j.jqsrt.2011.02.005, 2011.

Omar, A. H., Won, J.-G., Winker, D. M., Yoon, S.-C., Dubovik, O., and McCormick, M. P.: Development of global aerosol models using cluster analysis of Aerosol Robotic Network
(AERONET) measurements, J. Geophys. Res.-Atmos., 110, D10S14, https://doi.org/10.1029/2004JD004874, 2005.

Omar, A. H., Winker, D. M., Vaughan, M. A., Hu, Y., Trepte, C. R., Ferrare, R. A., Lee, K.-P., Hostetler, C. A., Kittaka, C., Rogers, R. R., Kuehn, R. E., and Liu, Z.: The CALIPSO Automated Aerosol Classification and Lidar Ratio Selection Algorithm, J. Atmos. Ocean. Tech., 26, 1994-2014, 2009.

Pachauri, R. K., Allen, M. R., Barros, V. R., Broome, J., Cramer, W., Christ, R., Church, J. A., Clarke, L., Dahe, Q., Dasgupta, P., Dubash, N. K., Edenhofer, O., Elgizouli, I., Field, C. B., Forster, P., Friedlingstein, P., Fuglestvedt, J., Gomez-Echeverri, L., Hallegatte, S., Hegerl, G., Howden, M., Jiang, K., Jimenez Cisneroz, B., Kattsov, V., Lee, H., Mach, K. J., Marotzke, J., Mastrandrea, M. D., Meyer, L., Minx, J., Mulugetta, Y., O’Brien, K., Oppenheimer, M., Pereira, J. J., Pichs-Madruga, R., Plattner, G.-K., Pörtner, H.-O., Power, S. B., Preston, B., Ravindranath, N. H., Reisinger, A., Riahi, K., Rusticucci, M., Scholes, R., Seyboth, K., Sokona, Y., Stavins, R., Stocker, T. F., Tschakert, P., van Vuuren, D., and van Ypserle, J.-P.: Climate Change 2014: Synthesis Report. Contribution of Working Groups I, II and III to the Fifth Assessment Report of the Intergovernmental Panel on Climate Change, edited by: Pachauri, R. K. and Meyer, L., IPCC, Geneva, Switzerland, 151 pp., 2014.

Rissler, J., Vestin, A., Swietlicki, E., Fisch, G., Zhou, J., Artaxo, P., and Andreae, M. O.: Size distribution and hygroscopic properties of aerosol particles from dry-season biomass burning in Amazonia, Atmos. Chem. Phys., 6, 471-491, https://doi.org/10.5194/acp-6-471-2006, 2006.

Seinfeld, J. H. and Pandis, S. N.: Atmospheric Chemistry and Physics, Second Edn., John Wiley \& Sons, Hoboken, New Jersey, 2006.

Tao, J. C., Zhao, C. S., Ma, N., and Liu, P. F.: The impact of aerosol hygroscopic growth on the single-scattering albedo and its application on the $\mathrm{NO}_{2}$ photolysis rate coefficient, Atmos. Chem. Phys., 14, 12055-12067, https://doi.org/10.5194/acp-14-120552014, 2014.

Wex, H., Neusüß, C., Wendisch, M., Stratmann, F., Koziar, C., Keil, A., Wiedensohler, A., and Ebert, M.: Particle scattering, backscattering, and absorption coefficients: An in situ closure and sensitivity study, J. Geophys. Res.-Atmos., 107, LAC 4-1LAC 4-18, https://doi.org/10.1029/2000JD000234, 2002.

Xu, W. Y., Zhao, C. S., Ran, L., Deng, Z. Z., Liu, P. F., Ma, N., Lin, W. L., Xu, X. B., Yan, P., He, X., Yu, J., Liang, W. D., and Chen, L. L.: Characteristics of pollutants and their correlation to meteorological conditions at a suburban site in the North China Plain, Atmos. Chem. Phys., 11, 4353-4369, https://doi.org/10.5194/acp-11-4353-2011, 2011.

Zhu, J., Xia, X., Wang, J., Zhang, J., Wiedinmyer, C., Fisher, J. A., and Keller, C.: Impact of Southeast Asian smoke on aerosol properties in Southwest China: first comparison of model simulations with satellite and ground observations, J. Geophys. Res.-Atmos., 122, 3904-3919, https://doi.org/10.1002/2016jd025793, 2017. 